\title{
Şizofrenide Psikojenik Polidipsiye Bağlı Gelişen Atrial Fibrilasyon: Bir Olgu Sunumu
}

\section{Atrial Fibrillation due to Psychogenic Polydipsia in Schizophrenia: A case report}

\author{
${ }^{1}$ Yaşar KAPICI, ${ }^{2}$ Sabri ABUŞ, ${ }^{1}$ Atilla TEKIN \\ ${ }^{1}$ Adıyaman Üniversitesi Tıp Fakültesi, Psikiyatri AD, Adıyaman, Türkiye \\ ${ }^{2}$ Kahta Devlet Hastanesi, Kardiyoloji Kliniği, Kahta, Adıyaman, Türkiye \\ Yaşar Kapıc1: https://orcid.org/0000-0002-9248-9426 \\ Sabri Abuş: https://orcid.org/0000-0003-2464-4970 \\ Atilla Tekin: https://orcid.org/0000-0002-2281-6719
}

\section{ÖZ}

Psikojenik polidipsi (PP), fizyolojik olan susama hissinden bağımsız olarak aşırı su alımıyla karakterizedir. PP ciddi tıbbi komplikasyonlara sebep olabilir. PP, sıklıkla şizofreni hastalarında görülür. Aşırı su alımına ve poliüriye bağlı olarak hipokalemi, hiponatremi ve hipokalsemi gibi elektrolit dengesizlikleri oluşabilir. Hiponatremi merkezi sinir sisteminde konfüzyon, konvülziyon, komaya neden olabilirken, hipokalemi QT uzamas1, supraventriküler veya ventriküler ektopik atımlar, supraventriküler ve hayatı tehdit eden ventriküler aritmilere neden olabilir $\mathrm{Bu}$ olguda psikojenik polidipsiye bağlı konfüzyon ile acil servise başvuran ve daha sonra atriyal fibrilasyonla takip edilen şizofreni hastasının literatür bilgileri ışığında tartış1lması amaçlanmıştır.

Anahtar Kelimeler: Atriyal fibrilasyon, psikojenik polidipsi, şizofreni

\section{ABSTRACT}

Psychogenic polydipsia (PP) is characterized by excessive water consume that is not related with physiological thirsting. PP can cause serious medical complications. PP is mostly accompanied with schizoprenia. Hypokalemia, hyponatremia and hypocalcemia may occur due to excessive water consume and polyuria. Electrolyte imbalances, such as hypokalemia, hyponatremia and hypocalcemia, may occur due to excessive water intake and polyuria. Hyponatremia can cause confusion, convulsions and coma in the central nervous system, whereas hypokalemia can cause QT prolongation, supraventricular or ventricular ectopic beats, supraventricular and life-threatening ventricular arrhythmias. In this case, it is aimed to discuss in the light of the literature of a schizophrenic patient with acute $\mathrm{AF}$ who admitted to the emergency department with confusion related to psychogenic polydipsia.

Keywords: Atrial fibrillation, psychogenic polydipsia, schizophrenia

Yayın Bilgisi / Article Info:

Gönderi Tarihi/ Received: 08/07/2020

Sorumlu Yazar / Corresponding Author:

Yaşar Kapıcı

$\begin{array}{ll}\text { Adıyaman Üniversitesi Tip Fakültesi Psikiyatri AD, Adıyaman } & \text { Kabul Tarihi/ Accepted: 07/01/2021 } \\ \text { Eğitim ve Araştırma Hastanesi, 02000, Merkez/Adıyaman } & \text { Online Yayın Tarihi/ Published: 05/03/2021 }\end{array}$

Tel: 05301230290

E-mail: dryasarkapici@gmail.com

Atıf/ Cited: Kapıcı Y, ve ark. Şizofrenide Psikojenik Polidipsiye Bağlı Gelişen Atrial Fibrilasyon: Bir Olgu Sunumu. 2021;6(1):150-154 doi: 10.26453 /otjhs. 766427

\section{Giriş}

Psikojenik polidipsi, giderek artan morbidite ve mortaliteye oranlarına sahip bir sağlık sorunudur. Çoğunlukla şizofreni hastalarında ve orta yaşlı kadın anksiyete bozukluğu hastalarında görülür. PP' ye bağlı semptomlar, sıklıkla günlük ortalama sıvı tüketiminin 10 litrenin üzerinde olduğunda ortaya çıkmaktadır. Kompulsif su içme davranışı gösteren hastalarda \%10-20 oranında hiponatremi görülür. Büyük miktarda sıvı alımına bağlı olarak idrar dilüe olur ve antidiüretik hormon (ADH) düzeyi düşer. ${ }^{1}$
PP olgularında hiponatremi dışında hipokalsemi ve hipokalemi gibi elektrolit dengesizlikleri, konfüzyon, deliryum ve koma tabloları da ortaya çıkabilir. ${ }^{2,3}$

Şizofreni hastalarında komorbid metabolik hastalıklara (obezite, diyabet gibi) veya tedavide kullanılan antipsikotiklerin yan etkilerine bağlı olarak kardiyak komplikasyonlar ortaya çıkabilir. Şizofreni hastalarında klozapin kullanımı ile ilişkili kardiyak sorunlar miyokardit, kardiyomiyopati, perikardiyal efüzyon ve subklinik kardiyotoksisite olarak tanım- 
lanmıştır. Atriyal fibrilasyon (AF), klozapin ve diğer atipik antispikotiklere bağlı olarak ortaya çıkabilen yan etkilerden biridir. Her ne kadar antipsikotiklere bağlı olarak gelişen AF'nin etiyolojisi tam olarak aydınlatılamamış olsa da kardiyak ve kardiyak olmayan birçok sebeple ortaya çıkabileceği bildirilmiştir. AF'ye sebep olabilecek kardiyovasküler bozukluklar arasında hipertansiyon, kalp kapak hastalıkları, sol ventrikül sistolik disfonksiyonu, hipertrofik kardiyomiyopati ve konjenital kalp hastalıkları bulunmaktadır. Diğer taraftan obezite, sigara kullanımı ve tiroid disfonksiyonu gibi kardiyak olmayan sebeplerin de AF için risk oluşturduğu bilinmektedir. ${ }^{4}$ Özellikle serum potasyum düzeyinin 3,3 mmol/L'nin altına düştüğü durumlarda kardiyak aritmi riskinin $\operatorname{arttı}_{1}$ bildirilmiştir. ${ }^{5}$

$\mathrm{Bu}$ yazıda, klozapin ile takip edilen bir şizofreni olgusunda ortaya çıkan PP ve AF klinikleri tartışılmiştır.

\section{OLGU SUNUMU}

Helsinki bildirgesi doğrultusunda hasta ve yakınlarından sözlü ve yazılı izin alınmıştır.

34 yaşında erkek hasta acil servise bilinç değişikliği ve ajitasyonu olması sebebiyle getirildi. Hasta yak1nının verdiği bilgilere göre, hastanın yaklaşık 16 yıldır şizofreni tanısı ile takipli olduğu ve klozapin 400 mg/gün ile ketiapin 100 mg/gün kullandığı öğrenildi. Hastanın yaklaşık bir aydır antipsikotik tedaviyi almadığı ve yaklaşık bir haftadır günde yaklaşık 12 litre su tükettiği bilgisi elde edildi. Daha önce de kompulsif su içmeye bağlı şikayetlerle acil servise ve psikiyatri polikliniğine başvurduğu öğrenildi. Hastanın yapılan nörolojik muayenesinde konfüzyonu vard1, yer ve zaman oryantasyonu bozuktu. Görüşme sırasında kooperasyonu kısıtlıydı. Yoğun terlemesi ve huzursuzluğu vardı. Yapılan kan ve idrar tetkiklerinde sodyum (Na) $117 \mathrm{mmol} / \mathrm{L}$, potasyum $(\mathrm{K}) 2,79 \mathrm{mmol} / \mathrm{L}$, klor $(\mathrm{Cl}) 85 \mathrm{mmol} / \mathrm{L}$, kalsiyum (Ca) 6,9 mg/dL ve idrar dansitesi 1000'di. Tam kan sayımı, böbrek fonksiyon testleri ve karaciğer enzimleri normal sınırlardaydı. Beyin görüntülemesinde herhangi bir patoloji yoktu. Vücut sicaklığ $36,5^{\circ} \mathrm{C}$, kan basınc1 150/110 mmHg, nabz1 150/dk, solunum h1zı 24/dk idi. İdrar ozmolaritesinin dilüe olması sebebiyle hastada uygunsuz antidiüretik hormon sendromu (SIADH) düşünülmedi. Çekilen elektrokardiyogramında (EKG) P dalgası yoktu, R-R mesafeleri düzensizdi, hızlı ventrikül yanıtlı $\mathrm{AF}$ izlendi ( dü ve hastanın yapılan transözefageal EKO'sunda sol atrial apendikste trombüs saptanmadi. Hasta monitörize edilerek propafenon $300 \mathrm{mg} / \mathrm{g}$ tedavisi başland1. AF tablosunun ne kadar süre önce başlad1ğ1 kesin olarak belirlenemese de, hasta yakınından alınan bilgiye göre, çarpıntı gibi kardiyak belirtilerin acil servise başvurudan yaklaşık 2 saat önce başladığ1 öğrenildi. Kardiyoloji servisine alınarak takip edildi. Dilüsyonel hiponatremisi ve hipokalemisinden dolayı hastanın oral sıvı alımı kısıtlanarak bolus $\% 3 \mathrm{NaCl}(0,5 \mathrm{mg} / \mathrm{L} /$ saat $)$ ve $\mathrm{KCl}$ infüzyon 6 meq/saat hızda başlandı.

Hastada 24 saat sonra yapilan EKG incelemesinde sinüzal ritm tespit edildi (Resim 2). 24 saat sonra yapılan laboratuvar incelemelerine göre $\mathrm{Na} 139$ $\mathrm{mmol} / \mathrm{L}, \mathrm{K} 3,78 \mathrm{mmol} / \mathrm{L}, \mathrm{Cl} 101 \mathrm{mmol} / \mathrm{L}$ ve $\mathrm{Ca} 9,5$ $\mathrm{mg} / \mathrm{dL}$ idi. Elektrokardiyografisinde herhangi bir kardiyak patoloji saptanmadi. Nörolojik muayenesinde bilinci açık ve oryantasyonu, kooperasyonu tam olarak değerlendirildi. Hastaya klozapin 100 $\mathrm{mg} / \mathrm{g}$ ve ketiapin $100 \mathrm{mg} / \mathrm{g}$ başlandı. Poliklinik kontrollerinde klozapin dozu birinci ayın sonunda 200 $\mathrm{mg} / \mathrm{g}$ 'a çıkarıldı. Birinci ayın sonunda yapılan muayenesinde kompulsif su içme davranışının ortadan kalktığı öğrenildi ve yapılan rutin laboratuvar incelemelerinde elektrolit düzeyleri normal sınırlar içerisinde saptand1.

\section{TARTIŞMA VE SONUÇ}

PP, özellikle şizofreni hastalarında görülmekle birlikte etiyolojisi tam olarak aydınlatılamamıştır. Bazı araştırmalar psikotik alevlenmenin PP'ye yol açtı̆̆1nı savunurken, diğerleri şizofreni tedavisinde kullanılan antikolinerjik ilaçların ADH salgılanmasını artırarak hastada kompulsif su içme davranışını tetiklediğini savunmaktadır. $^{6}$

Aşırı miktarda su alımı vücut elektrolit düzeylerini etkileyerek nörolojik ve kardiyak komplikasyonlara neden olabilir. Fazla miktarda alınan su öncelikle vücut sıvılarındaki sodyum düzeylerini düşürür. Vücut sodyum düzeyi 120 mmol/L'nin altına düşünce hastada bulantı, kusma, huzursuzluk, kas krampları, derin tendon reflekslerinde azalma, hipotermi gibi klinik semptomlar görülmeye başlanır. Sodyum düzeyinin $115 \mathrm{mmol} / \mathrm{L}$ 'nin altına düşmesi ile konfüzyon, koma ve ölüm gerçekleşebilir. ${ }^{7} \mathrm{Bu}$ olguda da, konfüzyon şeklinde bilinç değişikliği ortaya çıkan bir PP tablosu görülmektedir.

Polidipsik davranışı tedavi etmek ve hiponatremiyi önlemek için farklı ilaçlar önerilmiştir. PP çoğunlukla psikotik hastalarda görüldüğü için tedavide klozapin, olanzapin, lityum, risperidon, aripiprazol gibi psikotrop ilaçlar denenmiştir. Ancak bu ilaçların su içme dürtüsünden çok psikotik alevlenmeyi teda- 
vi ederek PP'yi önlemede etkili oldukları düşünülmektedir. Polidipsik davranışı azalttığı tespit edilen diğer ilaçlar fenitoin, bupropion ve propranololdür. Yapılan çalışmalarda ortaya konan tüm terapötik seçeneklerin kanıt düzeyi düşük olarak kabul edilmektedir. Bunun nedeni bu çalışmaların olgu sunumu, küçük olgu serileri veya küçük vaka kontrol grubu çalışmaları düzeyinde olmasıdır. Şizofreni hastalarında ortaya çıkan PP tedavisinde klozapin önemli bir tedavi alternatifi olarak bildirilmiştir. ${ }^{6}$ Bizim olgumuzda da, klozapin kullanmadığı dönemde PP ortaya çıkmış ve klozapin tedavisi ile PP birinci ayın sonunda tamamen ortadan kalkmıştır.

Hipokalemi, voltaj kapılı kanallarda potasyumun iletkenliğini azaltarak aritmileri arttırır. Hipokalemi kardiyak iletimin repolarizasyon fazında kardiyak iyonları etkileyerek hiperpolarizasyonu azaltır. Kismen depolarize olan hücre membranı spontan uyarımlar yoluyla ventriküler aritmilere neden olur. Hipokalemide EKG'de ST segmentinde değişiklikler görülür. Hipokalemide $\mathrm{T}$ dalgasının genliği azalır, ters T dalgası oluşur, QT aralığında uzama meydana gelir ve U dalgasının ortaya çıkar. Hipokalemi ayrica atriyal fibrilasyon ve solunum depresyonuna neden olabilir. ${ }^{8}$ Bizim olgumuzda, PP ile ortaya çıkan hipokalemi tablosu ile ilişkili olduğu düşünülen AF söz konusudur. Her ne kadar AF etiyolojisi yeterince aydınlatılamamış olsa da, bizim olgumuzda PP'ye bağlı olarak gelişen elektrolit dengesizliğinin AF'ye sebep olabileceğini düşündük. Herhangi bir kardiyak hastalık veya anomali öyküsünün olmamas1, tiroid fonksiyonlarının normal sınırlar içerisinde olmas1, diyabet ve hipertansiyon gibi sistemik hastalığının olmaması, alkol kullanımının olmaması bu hastada akut gelişen AF tablosunda elektrolit imbalansının görece en önemli etiyolojik faktör olarak yorumlanmasına sebep olmuştur. Ayrıca hastanın antipsikotik ilaçları yaklaşık bir aydır kullanmıyor olması, antipsikotiklere bağlı gelişebilecek AF tanısından uzaklaştırmıştır.

Sonuç olarak, şizofreni hastalarında bu olguda bahsettiğimiz gibi tedavisiz dönemlerde PP ve buna bağlı komplikasyonlar gelişebilir. Her ne kadar PP'de çoğunlukla hiponatremi görülse de, hipokalemi ve hipokalemiye bağlı kardiyak komplikasyonlar açısından da dikkatli olunmalıdır.

Etik Komite Onayı: Bu olgu sunumu için etik kurul onayı gerekmemektedir. Hasta ve yakınlarından sözlü ve yazılı izin alınmıştır.

Çıkar Çatışması: Yazarlar herhangi bir çıkar çatışması belirtmemektedir.
Yazar Katkuları: Klinik Değerlendirme - YK, SA. Literatür Tarama - YK, SA, AT. Makale Yazımı YK, SA, AT

Hakem değerlendirmesi: Dış bağımsız.

\section{KAYNAKLAR}

1. Spanevello C, Banava E, Gachoud D, Berney A, Tzartzas K, Maccaferri GE. Psychogenic polydipsia: a (still) unknown psychosomatic entity. Rev Med Suisse. 2020;16(681):318-321.

2. Perestrelo J, Teixeira B. Psychogenic polydipsia and hyponatremia-A side effect of psychosis: a review with a case report. J Bras Psiquiatr. 2016;65(3):300-303. doi:10.1590/00472085000000135

3. Sailer CO, Winzeler B, Christ-Crain M. Primary polydipsia in the medical and psychiatric patient: characteristics, complications and therapy. Swiss Med Wkly. 2017;147:w14514. doi:10.4414/ smw.2017.14514

4. Andrade J, Khairy P, Dobrev D, ve ark. The clinical profile and pathophysiology of atrial fibrillation: relationships among clinical features, epidemiology, and mechanisms. Circ Res. 2014;114(9):1453-1468.

5. Weiss JN, Qu Z, Shivkumar K. Electrophysiology of hypokalemia and hyperkalemia. Circ Arrhythm Electro-physiol. 2017;10(3):e004667.a. doi:10.1161/CIRCEP.116.004667

6. Kirino S, Sakuma M, Misawa F, ve ark. Relationship between polydipsia and antipsychotics: a systematic review of clinical studies and case reports. Prog Neuropsychopharmacol Biol Psychiatry. 2020;96:109756. doi:10.1016/j.pnpbp.2019.109756

7. Yıldız G, Kayataş M, Candan F. Hyponatremia; current diagnosis and treatment. Turk Neph Dial Transpl. 2011;20(2):115-131. doi:10.5262/ tndt.2011.1002.02

8. Tazmini K, Frisk M, Lewalle A, ve ark. Hypokalemia promotes arrhythmia by distinct mechanisms in atrial and ventricular myocytes. Circ Res. 2020;126(7):889-906. doi:10.1161/CIRCRESAHA.119.315641 


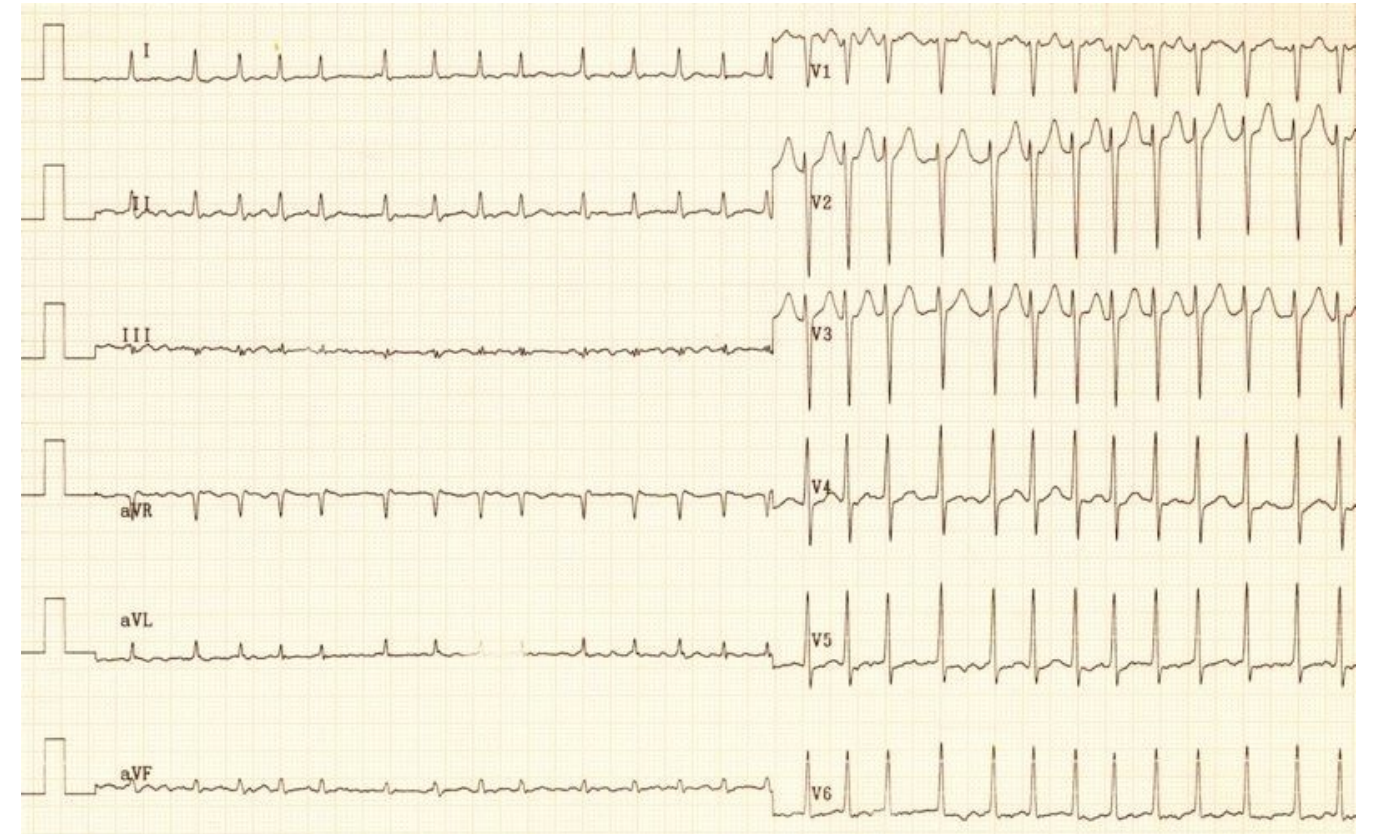

Resim 1. Hastanın çekilen EKG'si ve atriyal fibrilasyon. 


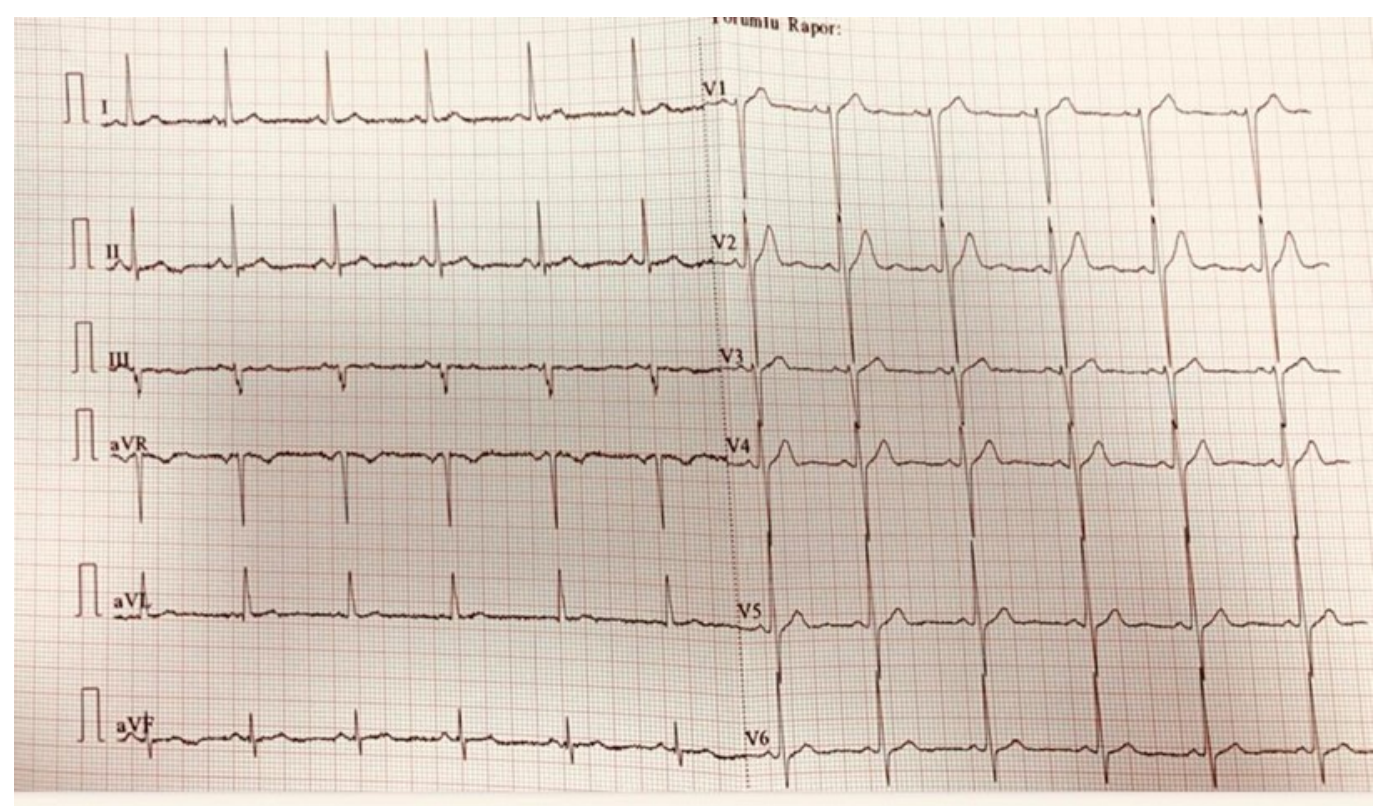

Resim 2. Hastanın tedavi sonrası yapılan EKG incelemesi. 